\title{
Organizational and cultural factors that promote creative best practices in the public rehabilitation program: Findings from a four-state multiple case study
}

\author{
Susan G. Sherman ${ }^{\mathrm{a}, *}$, Michael J. Leahy ${ }^{\mathrm{a}}$, Roy Del Valle ${ }^{\mathrm{a}}$, Catherine A. Anderson ${ }^{\mathrm{b}}$, \\ Timothy N. Tansey ${ }^{\mathrm{c}}$ and Katherine Lui ${ }^{\mathrm{d}}$ \\ ${ }^{a}$ Michigan State University, East Lansing, MI, USA \\ ${ }^{\mathrm{b}}$ University of Wisconsin-Stout, Menomonie, WI, USA \\ ${ }^{\mathrm{c}}$ University of Wisconsin-Madison, Madison, WI, USA \\ ${ }^{\mathrm{d}}$ Metropolitan State University, St Paul, MN, USA
}

Revised/Accepted July 2014

\begin{abstract}
The state-federal vocational rehabilitation system is tasked to demonstrate accountability for employment outcomes of persons with disabilities. State VR agencies have sought to evaluate existing practices, and in areas that existing practices leave room for improvement, create the conditions for innovation to occur. The purpose of this article is to identify promising organizational and cultural factors that appear to promote best practices in the public vocational rehabilitation program. A multi-stage study utilizing the Consensual Qualitative Research (CQR) was conducted involving four high performing state VR agencies to discover emerging and promising organizational practices leading to improvements in employment outcomes of people with disabilities. The comprehensive examination revealed specific organizational practices, culture and structural elements that encourage and support the development of innovative, effective service delivery practices. Given the complexity of service provision and the increasing demand for successful outcomes, VR agencies must develop organizational cultures that facilitate transformational learning by employing evidence-based practices that lead to successful outcomes for agency consumers.
\end{abstract}

Keywords: Organizational culture, learning organization, leadership, state vocational rehabilitation agency, evidence-based practices, competing values framework

\section{Introduction}

The State/Federal Vocational Rehabilitation (VR) program originated through federal legislation in 1920 with the Smith-Fess Act (Patterson, Bruyere, Szymanski, \& Jenkins, 2005) and remains some 94 years later as the primary public sector provider of VR services for individuals with significant disabilities in this country.

*Address for correspondence: Susan G. Sherman, Office of Rehabilitation and Disability Studies, Michigan State University, 455 Erickson Hall, East Lansing, MI 48824, USA. E-mail: sherwatsusan@comcast.net.
There has been mounting pressure in recent years to demonstrate accountability for employment outcomes of those served by the state-federal system through the development and use of evidence-based practices. This has led to an increased focus on research dedicated to improving practice and the translation, dissemination, and utilization of that knowledge throughout the 83 state-federal agencies that represent the public VR program. The emphasis of the National Institute of Disability and Rehabilitation Research (NIDRR) on knowledge translation of research findings into practice highlights the paucity of evidence based-practice 
and sets the agenda for the work that needs to be done. As indicated by Pruett, Swett, Chan, Rosenthal, and Lee (2008), the powerful question posed by Paul (1967) years ago, "What treatment, by whom, is most effective for this individual with that specific problem, and under which set of circumstances?" (p.111) remains for the most part unanswered within the public rehabilitation program (Leahy, Thielsen, Millington, Austin, \& Fleming, 2009).

Although federal mandates from the Rehabilitation Services Administration (RSA) for public VR programs initially focused on the design of program evaluation systems and the collection, analysis and reporting of data on the impact of services, the focus has evolved over the years to emphasize how these data are used for continuous improvement in the delivery of services and the outcomes achieved. In recent years there has also been increased attention on the concepts of quality assurance systems or plans, evidenced-based practice (EBP), and knowledge translation (KT) efforts within the healthcare, disability and rehabilitation arenas. These initiatives are associated with the use of quantitative and qualitative data obtained through research and evaluation efforts to inform policy, practice and continuous improvement strategies for organizations that serve people with disabilities. One of the most critical issues that affects the quality and usefulness of program evaluation, research, and continuous improvement efforts is the degree to which the leadership and management of the organization value such efforts. This is similar to the development of a learning culture within organizations that creates and sustains an environment that supports the creation of best practices provides the resources to rigorously examine the impact of these promising practices and interventions on employment outcomes of the consumers they serve. For example, if the State Director and leadership in a public rehabilitation program do not value and invest in program evaluation and research efforts, those activities will be minimally effective and only serve to satisfy compliance with regulatory standards (Leahy et al., 2009).

The purpose of this paper is to provide an in depth discussion and examination of the findings from a multiple case study undertaken by the RRTC-EBP VR to identify promising best practices and organizational factors associated with successful employment outcomes for consumers served in the public VR program (Leahy et al., 2013). Although the rigorous methodology employed in this multistate study through the use of Consensual Qualitative Research (CQR) and the find- ings related to promising best practices are presented and discussed in separate articles within this special issue (Anderson, Leahy, Del Valle, Sherman, \& Tansey, 2014; Del Valle et al., 2014), the findings and discussion of the organizational environment and cultural factors identified in the study will be the focus of this paper.

\section{Literature review}

\subsection{Culture}

Culture is the "medium through which leadership travels and impacts organizational performance" (Packard, 2009). Culture is closely tied to an organization's top leadership. An organization's culture guides the organization's behavior (Giberson et al., 2009). One of the definitions of organizational culture is the "organizational values, beliefs and hidden assumptions that organizational members have in common" (Sanz-Valle, Naranjo-Valencia, Jimenez-Jimenez, \& Perez-Caballero, 2011). Culture provides shared meanings and helps interpret information provided and events that occur in the organization (Giberson et al., 2009). Meaning and information are then passed down and taught to new members as a way of handling organizational problems.

Culture can influence employee views of what is and what is not important, it allows an individual to develop knowledge that can impact organizational learning, and it creates processes by which knowledge is created, approved and distributed. Schein (1984) defined different levels of organizational culture as basic assumptions that are unconsciously-held learned responses. These learned responses determine (a) how group members perceive, think and feel; (b) values and beliefs that are part of an individual's consciously held concepts that are used to justify beliefs and actions; and (c) objects and physical settings that include office layouts and organizational symbols. Leaders rely on these cultural precepts to manage people, to develop strategy and to implement organizational change.

Schultz (2008) noted that culture was the collective practices of the organization. He stated that, "organizations thrive when the organizational culture facilitates buy-in, creativity, and personal involvement of professional staff (p.40)." The culture of an organization influences the behavior of those in the organization and can serve as a mechanism for bringing employees together to enhance organizational goals and increase productivity (Schraeder, Tears, \& Jordan, 2005). In 
organizations, culture is the shared meaning and understanding of the organization (Giberson et al., 2009). Organizational culture affects all facets of the organization including policies, procedures, and operational strategies. The culture of an organization can help or hinder an organization's ability to accept change, be innovative and encourage and create new knowledge from which employees can be more productive and meet customer need (Rijal, 2010; Schraeder et al., 2005; Brown, 1992). An organization's culture can also impact innovation and development of the organization as a learning environment.

\subsection{Culture and the learning organization}

A learning organization develops new knowledge and insight from the common experiences of its employees and has the potential to promote positive behaviors and improve the organization's capabilities (Sanz-Valle, Naranjo-Valencia, Jimenez-Jimenez, \& Perez-Caballero, 2011). Transitioning state VR agencies from administrative entities (Herbert, 2004; Herbert \& Trusty, 2006; Schultz, 2007; Schultz, 2008; Bezyak, Ososkie, Trice \& Yeager, 2010) into learning organizations that develop and promote evidence based service delivery practices is necessary to enhancing program outcomes and creating environments that facilitates innovation. Learning organizations are better at retaining staff, encouraging innovation, developing evidence-based practices to improve organizational performance (Schultz, 2007; Packard 2009). According to Sessa \& London (2006), three levels of learning occur within organizations: 1) Adaptive learning occurs when an organization reacts to and attempts to resolve an issue in a manner that is not conscious or reflective in nature, 2) Generative Learning occurs when individuals seek out new knowledge about a subject or issue, and 3) Transformational Learning occurs when a group of individuals experience a shift in the way they perceive their environment (Mezirow, 2000; Schultz, 2007). The greatest benefit for an organization occurs through generative and transformational learning (Schultz, 2007).

De Long \& Fahey (2000) suggest that culture shapes organizational learning in four ways: "1) culture shapes employee assumptions about whether knowledge is important or not and what knowledge is worth managing, 2) culture allows individual knowledge to become organizational knowledge, 3) culture shapes the processes by which new knowledge is created, legitimated and distributed, and 4) culture creates the context for social interaction that ultimately determines how effec- tive an organization can be at creating, sharing and applying knowledge".

In an attempt to define organizational culture in relation to organizational learning, Cameron and Quinn (1999) proposed the Competing Values Framework (CVF). The CVF is an extremely useful tool for analyzing organizational culture and designing a course for changing such culture in a way to effectively promote sweeping strategic initiatives (Lincoln, 2010). Quinn and Rohrbaugh (1983) explained CVF in terms of two major dimensions that included four major quadrants representing opposite assumptions. Dimension 1 ranges from flexibility and discretion to stability and control in the organization. Dimension 2 ranges from internal focus and integration to external focus and differentiation in the organization. The four major quadrants defined by these two axes are labeled as clan, market, hierarchy, and adhocracy (Cameron \& Quinn, 2006; Naranjo-Valencia, Jimenez-Jimenez, \& Sanz-Valle, 2011). Figure 1 illustrates the CVF model.

Clan culture, is collaborative in nature, has an emphasis on flexibility, internal maintenance, teamwork, employee involvement, empowerment, cohesion, participation, and corporate commitment to employees. In this culture, leaders and management encourage mentoring, nurturing, trust, and sharing. Market culture is externally focused and decision-making is based on data analysis. The emphasis is on productivity, profitability, market share and winning. Leaders and managers are strategic, competitive, and results oriented (Giberson et al., 2009; Lincoln, 2010; Sanz-Valle et al., 2011; Millington \& Schultz, 2009).

Hierarchical culture focuses on the internal organization (i.e. structured bureaucracy) and is control oriented.

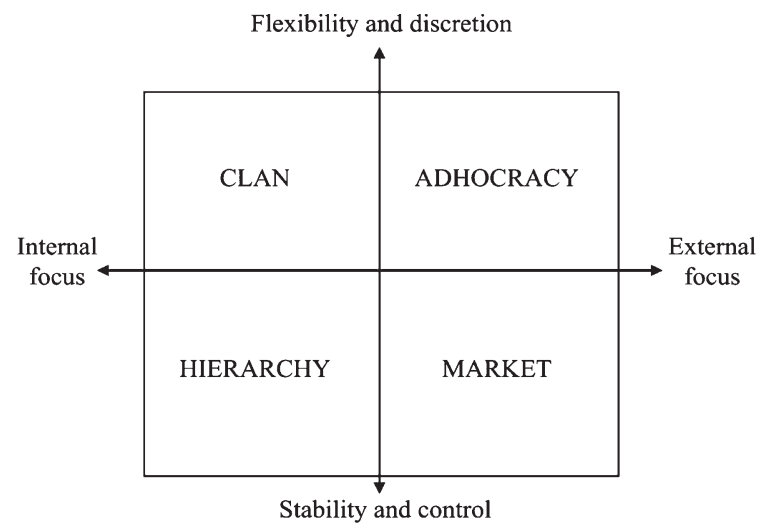

Source: Cameron and Quinn (1999)

Fig. 1. Competing Values Framework (CVF). 
Decision-making is centralized with information coming down through the chain of command. In hierarchical systems, the use of authority by those in administrative roles, efficiency, cost containment, and compliance to rules are of paramount importance (Sanz-Valle et al., 2011; Millington \& Schultz, 2009). Conversely, adhocracy is externally focused and emphasizes flexibility or dynamism, adaptability, and change. Decision-making is decentralized and creativity, entrepreneurship, and risk-taking are expected and valued. In this culture, teams are formed around projects and communication flows up the chain of command. As a result, leaders and managers in adhocracy systems value innovation and building partnerships with external stakeholders. Such culture promotes survival in an uncertain, ambiguous, and turbulent environment (Lincoln, 2010; Millington \& Schultz, 2009; Sanz-Valle et al., 2011).

Different organizational cultures have different impacts on organizational learning (Sanz-Valle et al., 2011). Leaders in these programs have often overseen hierarchical cultures (Millington \& Schultz, 2009) that focus on internal organization and control (Giberson et al., 2009). Characteristics of these types of hierarchical cultures include following the rules, regulations and norms. Leadership styles emphasizing this type of culture has negative effects on learning and therefore does not encourage movement to a learning organization.

\subsection{The Culture of Leadership}

No matter how large the organization, agency leaders need to develop an organizational culture that encourages innovation at all levels and creates a learning environment leading to sustainable synergy. Leadership of an organization can be defined as "the process by which leaders influence the attitudes, behaviors, values of others toward organizational goals" (Chi, Lan, \& Dorjgotov, 2012) or a "process by which an individual influences a group of individuals to achieve common goals" (Packard, 2009). The effect of leadership behaviors on organizational culture is of importance to organizational success and effectiveness. Leadership is an important variable that affects the performance of an organization (Packard, 2009). The leadership behavior of an organization creates, either knowingly or unknowingly, the culture of the organization in which staff operates. Leadership that facilitates a culture that allows for the creation of a learning organization encourages the development, acquisition, transformation, and dissemination of new knowledge that can foster innovation leading to effective best practices (Rijal, 2010).
Organizational culture is one of the management tools available to leaders of organizations to shape employee performance (Lincoln, 2010; Giberson et al., 2009). Culture can improve employee performance by reducing job stress and enhancing the confidence and commitment of employees (Lincoln, 2010; Shahzad, Luqman, Khan, \& Shabbir, 2012).

Schein $(1984,1992,1993,1997)$ has done extensive research into organizational culture and leadership. Schein suggests that organizational learning should be looked at in terms of an organization's culture (Schein, 1992, 1993; Lucas \& Kline, 2008). In his basic model, Schein noted that behaviors, values and basic assumptions, such as ways of thinking, perceiving and reacting, are powerful forces that stabilize organizations (Shahzad et al., 2012). The convergence of attitudes, behaviors and values of those in an organization is considered leadership (Chi, Lan, \& Dorjgotov, 2012). Leadership, particularly at the chief executive or director level, is tied to an organization's culture. The leadership of an organization, through strategic and operational decisions, forms the basis of shared values and assumptions that form an organization's culture (Giberson et al., 2009).

Personality traits of leaders influence culture and are one way to understand the connection between the leader and his/her organization. Bass (1985) defined a transformational leader as "one who motivates followers to do more than they originally expected to do". Transformational leaders expand and can change the interests of their followers, and generate awareness and acceptance of the purpose and mission of the organization. Transformational leadership consisted of three components: 1) charismatic leadership: where the leader exhibits behaviors that subordinates admire and appreciate; 2 ) intellectual stimulation: where the leader encourages innovation and creativity; and 3) individualized consideration: where the leader finds ways for followers to identify goals and enables opportunities to achieve those goals (Packard, 2009). Transformational leaders, who believe in the principle of power with, rather than power over, make strategic and operational decisions that impact the culture of their organizations and influence those who work within the culture. Transformational leaders encourage creation of learning environments that support staff in implementing best practices that lead to greater organizational success (Tuft, 2012).

Senge (1994) popularized the term "learning organization" in the 1990's in his book The Fifth Discipline. $\mathrm{He}$ identified three leadership roles needed to build 
a learning organization: leaders as designers, leaders as teachers, and leaders as stewards (Senge, 1994). Creating a transformational culture requires support of innovation, transformation, and change. Leaders of learning organizations must provide a clear and attractive vision of the organization's future that creates commitment from followers in achieving goals (Warrick, 2011). Transformational leaders see a need for change, create a new vision and obtain from followers a commitment to organizational change (Rijal, 2010). These leaders work with their followers to embrace uncertainty and facilitate followers understanding of the goals of the learning organization. Transformational leaders build commitment and then set about empowering their followers to "look beyond their own self-interest for the good of the group" (Stone, Russell, \& Patterson, 2004). In order to transform their organization, transformational leaders recognize the need for change, create a new vision and institute the change (Warrick, 2011; Yang, Wu, Chang, \& Chien, 2011). In light of the above discussion related to organizational culture and leadership, the following section presents the findings from the study involving four high performing state-federal VR agencies.

\section{Methodology}

This study utilized a qualitative, multiple-case study design with four state VR programs serving as individual sites. As noted by Stake (2005), specific cases should be selected intentionally rather than randomly to examine particular research questions comprehensively and in greater depth. The four state agencies were selected to participate based on previous research findings indicating levels of high-performance, as well as a peer-nomination process (Fleming, Del Valle, Kim, \& Leahy, 2013). For a more detailed review of the methodology utilized in this study interested readers are encouraged to review another article in this special issue by Anderson, Leahy, Del Valle, Sherman \& Tansey (2014).

Consistent with protocol recommended by Yin (2009) and Stake (2006), the same methodological framework was used across cases thereby enhancing representativeness and robustness when consistent findings emerged across sites. A modified Consensual Qualitative Research (CQR) methodology was used to examine the data and provided a systematic, rigorous approach to analysis (Hill, Thompson, \& Williams, 1997; Hill \& Williams, 2012).
The research question, "What are the best models of effective practice, policy, and procedures among state VR agencies that result in the creation of an environment that promotes innovation and the effective delivery of services to assist individuals with disabilities to achieve employment outcomes?" was specifically proposed to identify organizational and cultural factors associated with creating a culture that promoted best practices in the public VR program. The question was designed to elicit information from all case study participants regarding the organizational and cultural factors they believe were related to services and interventions they felt were evidence-based, innovative, or promising practices that lead to improved employment outcomes within the VR system. Although the researchers requested and received a substantial amount of administrative reports from each of the four states studied, the case study data collected through interviews and focus groups provided very helpful, thorough information in addressing the research question at hand.

\subsection{Participants}

Purposive sampling (Fraenkel \& Wallen, 2003), a technique commonly used in qualitative research, was used to select participants across three distinct organizational levels with the state-federal VR program-leaders, mid-level managers, and counselors. Researchers worked closely with the VR administrator or their designee in the respective state agencies given that these individuals were well positioned to identify key staff members across organizational levels. Preliminary contact was made with the administrator of each state VR agency to establish an acceptable timeframe for conducting semi-structured interviews and focus groups with participants. Leaders were asked to extend an invitation to identified staff to participate in specified research activities and were integral in encouraging engagement with the research team. The researchers employed this technique with the consideration that real or perceived power discrepancies may exist among staff at varying hierarchical and seniority levels. However, given that access to key staff engaged with emerging, promising, innovative, or evidence-based practice was imperative in addressing the research question, the investigators agreed that agency leaders were in the best position to assist with sampling.

Consistent with the conceptual design, data were collected from staff representing three distinct organizational levels within each state including the administrator and members of the senior management 
team, supervisors and mid-level managers, and rehabilitation counselors (Leahy, Del Valle, Fleming \& Kim, 2012). The interviews and focus groups were conducted in-person in each state over a two to three day timeframe. Across the four state sites, a total of 154 individuals including four state directors, 25 senior leaders, 56 mid-level managers, and 73 VR counselors participated in the study. The multiple case studies of the four VR state agencies selected were conducted between June 2012 and January 2013.

\subsection{Semi-structured interviews and focus groups}

Semi-structured interview techniques provide an open-ended, less structured and flexible approach to gathering data from participants using a participatory, conversational approach (Merriam, 2009). Sixty-minute semi-structured interviews were individually conducted with VR agency leaders including the directors of the VR programs, VR for the blind programs, client services, and other senior management staff. Group interviews, also referred to as focus groups; provide an opportunity for researchers to facilitate discussion among participants when addressing the research question(s). It was particularly important to foster and record rich participant discussion given that this study was exploratory in nature (Fontana \& Frey, 2005). Ninety-minute focus groups were conducted with regional and district directors, specifically those serving in mid-level management positions. Additional 90-minute focus groups comprised of approximately 10-15 participants each were also conducted with VR counselors and staff in each of the four case study states. Although counselor participation was prominent among the third organizational level of data collection, other staff including trainers also contributed to the discussion. Representation of staff across the three organizational levels was important in specifying environmental factors that affect receptiveness to innovation and the adoption of promising or evidence-based practice.

\subsection{Data analysis using $C Q R$}

A modified approach to the Consensual Qualitative Research (CQR) process developed by Hill and colleagues (1997) was used for this study. CQR provides a systematic approach to gathering and analyzing qualitative information by multiple researchers using semi-structured data collection techniques. Researchers must reach consensus about inherent meaning in the data before confirming the domain, core idea, and cross-analytical phases. Additionally, a hallmark feature of CQR involves use of at least one auditor who is responsible for reviewing the work of the primary researchers. The auditor poses objective opinions and recommendations regarding the researchers' adherence to original source data to ensure representativeness and trustworthiness and reduce potential group-level bias (Schlosser, Dewey, \& Hill, 2012). As noted by Ladany, Thompson, and Hill (2012), an external audit of the cross-analysis phase, particularly in comprehensive studies involving substantial data, is important and enhances stability of the findings.

\section{Results and discussion}

The results of the cross analysis on research findings identified common domains across the four agencies studied in relation to the primary research question that guided this portion of the larger study. Each of these domains representing organizational and cultural factors associated with creating an atmosphere conducive to innovation and best practices will be presented and discussed below. Multiple domains were noted across the three organizational levels within each state agency for leaders, mid-level managers and selected counselors and other staff involved with the agency's innovations and best practices. Below is a summary of the multiple domains that appeared at each organizational level, including domains unique to individual agencies. The movement from hierarchal culture to a culture of adhocracy that facilitates a learning organization has been a key to the success of each of these high performing VR agencies. Table 1 provides an overview of environmental and cultural factors found across all organizational levels, within the four-state sample. Each is follow by a brief description.

\subsection{Culture}

There was agreement that effecting change in the organizations' culture is necessary to making substantial changes in agency operations and service delivery practices enhancing service quality and employment outcomes for customers. Included in culture is the notion, as one agency described it, of trying to instill "a culture of critical and smart thinking before you do." This need for organizational change by agency leaders is supported by the literature. Because culture is an integrative process, improving performance in a time of 
Table 1

Environmental and Cultural Factors, by state, across all organizational levels

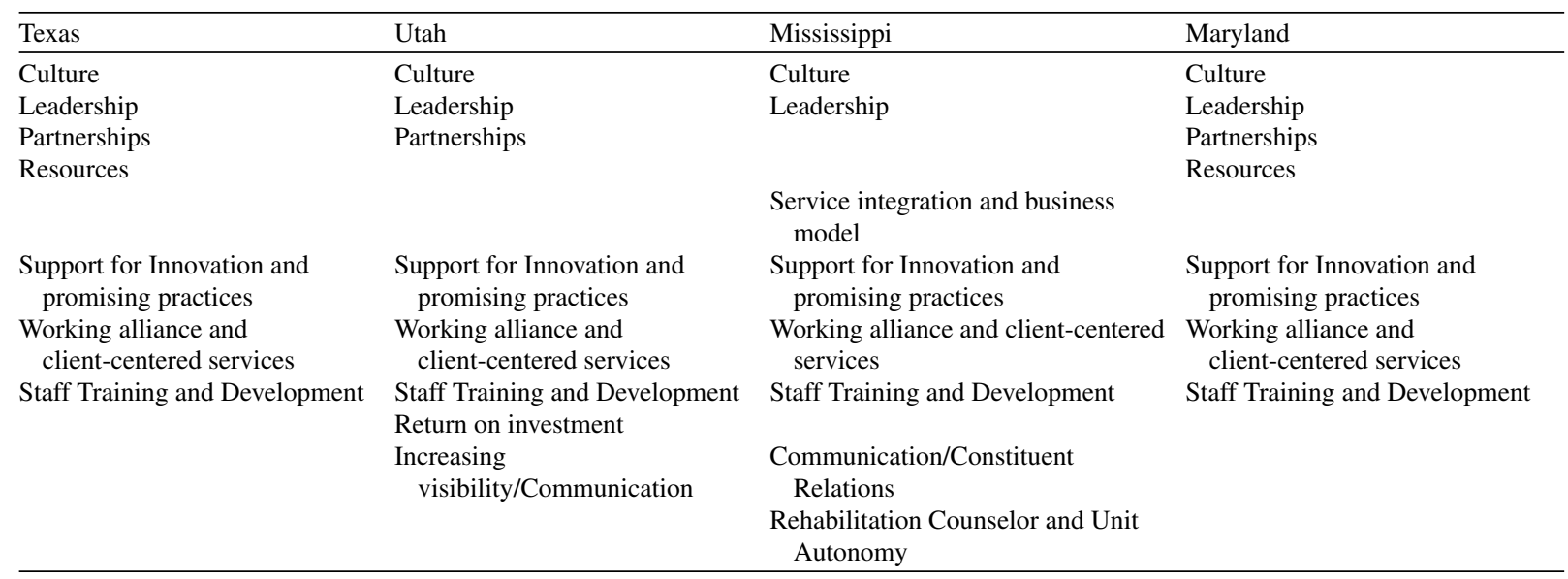

diminished resources requires successful VR agencies to change from traditionally hierarchical culture, with a focus on control to a culture of adhocracy, focused on flexibility, risk taking, partnerships and innovation. One VR agency described an agency culture of development and promotion that would allow adoption of a transformational agenda; encouraging best practices to be adopted and innovation to occur. In another agency, culture was considered the environment where all staff is "very encouraged to be creative, be visionary to deliver the agency message, goals and mission."

\subsection{Leadership}

Agency leaders were aware that their responses to the innovative ideas brought forward must demonstrate support for agency staff. Credit was given by mid-managers, counselors and staff to agency leaders for instituting organizational changes leading to a less bureaucratic and a more flexible and responsive agency. The culture a leader creates, can "strongly influence the behaviors of employees" (Sanz-Valle et al., 2011). Research clearly shows moving to an adhocracy focused flexible and adaptable culture has a positive effect on employees and supports organizational learning and risk-taking (Giberson et al., 2009; Sanz-Valle et al., 2011; Yang, Wu, Chang, \& Chien, 2011). Counselors and staff clearly appreciated the accessibility of agency leaders. Comments such as "support of your supervisor to be creative and to be able to discuss the best way to handle things" and "my supervisor supports me in trying new things" were common themes from counselors and staff. Leaders in learning organizations need to be flexible and adaptive, striving to bring out the best in their followers (Rijal, 2010). In the organizations included in this project, the leaders believed that "the way we walk, talk act, supporting ideas, being open to people" is encouraging innovation and use of best practices. Chan and Reudel (2005) have noted that "rehabilitation agency supervisors have the potential to make a significant impact on the issue of retention" (Schultz, 2007). Counselors and staff also recognized that continuity in agency leadership was an important element of agency success.

\subsection{Support for innovative and promising practices}

Leaders of agencies encouraged and supported innovative ideas throughout all levels of the organization. These leaders encouraged communication and autonomy and were open to and encouraging of staff ideas at all levels of the organization. The creation of a shared vision, effective communication, and support for innovation are hallmarks of transformational leadership. Organizations that thrive facilitate a culture of buy-in, creativity and the personal involvement of professional staff (Schultz, 2008).

Collaboration with community partners and requiring field staff to be heavily involved with service providers through constant contact and communication were viewed as the foundation for successful innovative ventures. Hierarchical cultures tend to inhibit innovation due to their internal focus on control and sta- 
bility (Giberson et al., 2009). The research supports that movement from hierarchical to adhocracy culture fosters creativity and innovation in these high performing agencies.

\subsection{Partnerships}

The relationship with all partners including consumers, employers, community rehabilitation programs and other state agencies was valued by VR agency staff at all levels. Inter and intra-agency partnerships were considered critical components of service provision. The agencies in the study worked closely with several entities to ensure that their partners' needs were met through collaborative working relationships and seamless service delivery.

\subsection{Staff training and development}

A learning organization brings out the best in its employees and has a culture where individuals are encouraged to enhance their skills and performance and share knowledge and expertise to improve the organization. Schultz (2008) discussed how transformational learning is the overlap of clinical supervision and professional development. A highly trained staff is essential to achieve the working alliance and providing professional services. Training in specific targeted populations such as blindness, deafness, autism, transition age youth and multicultural counseling are practices the four states employed to enhance service delivery and employment outcomes for agency customers. Training initiatives at these agencies were not just limited to successful job task completion but counselors and staff were also encouraged to "look for opportunities for personal growth and advancement". A continuous learning orientation in these agencies encouraged development of staff and new ideas that assisted these organizations to "think outside the box" and to develop new ways to address consumer needs. Continuous learning is necessary for organizations to have the "ability to meet the changing needs in rehabilitation service delivery" (Schultz, 2007).

\subsection{Working alliance and client-centered services}

Client-centered services or the working alliance were used to describe the focusing of staff on professionalism in rehabilitation counseling services. These agencies believed that rehabilitation counselors should be performing their duties in the counselor role rather than the case management role inherent in their positions. Counselor statements reflected a feeling of being connected to the counseling components of rehabilitation counseling. Client-centered services incorporate the holistic view of clients into rehabilitation planning, rather than limiting clients to a tightly focused view of functional abilities and mechanical job placement. These agencies realized that client self-actualization is as important as employment outcomes.

Along with the common agency domains, the research yielded unique agency domains within the four states. Although these efforts were not duplicated in the other sample states, the researchers determined the following were important to report and briefly discuss.

\subsection{Return on investment}

Marketing the benefits of services and the return on investment to state policy makers has demonstrated the value of services in measureable terms to both internal and external personnel and has allowed one agency to stabilize and expand the scope of their program over time. The culture of understanding the return-oninvestment of specific initiatives or services support the capacity of this agency to consider sustainability of these projects beyond the time-limited support that may be available from federal or state sponsors.

\subsection{Service integration and business model}

Adhocracy culture recognizes that innovation and change is necessary to enable the organization to take charge of shaping its own future (Giberson et al., 2009). Rather than relying on referrals to external agencies, one agency is providing service integration and coordination, when feasible and deemed productive, directly to clients. This VR agency has incorporated a business model that has produced its own unique structure. The agency has embedded a 501(c3) within its structure in order to provide flexibility. It has a client first approach, providing high quality services that focus on outcomes. The organization maintains relationships with legislators, employers, partners and the public and has been successful in selling its story.

\subsection{Increasing visibility and communication/constituent relations}

Effective communication enables transformational leaders to create a shared vision that enables employees to understand the goals and aspirations of the 
organization (Rijal, 2010). A focus on increasing visibility for one agency has increased the awareness of its VR program, the consumers the program serves, and the benefits of providing services for individuals with disabilities and the community. This agency views visibility, communication and constituent relations as critical to their ongoing efforts to secure community support for the program, engage partners in a dialog regarding joint services, and communicate effectively with the state's legislature to preserve, and ultimately expand, funding for the department's programs. Another agency views communication as a critical interaction at all levels of the agency and operates an Office of Communications and Constituent Relations (OCCR) specifically designated to address questions and requests from legislators and assist with public relations campaigns.

\subsection{Rehabilitation counselor and unit autonomy}

A hallmark of adhocracy culture is flexibility in service provision (Giberson et al., 2009; Sanz-Valle et al., 2011; Millington \& Schultz, 2009). In order to meet the service needs of individual clients, one state agency empowers staff in their district offices to have the flexibility to alter services to meet the needs of the surrounding communities. This agency provides counselors with the ability to refer internally for a range of different services based on individual need.

\subsection{Resources}

The semi-structured interviews revealed agency leaders who are committed to acquiring, developing, and disseminating resources needed for field operations. An organization's culture is formed through the strategic and operational decision of its top leaders (Giberson et al., 2009). Leaders in an adhocracy culture focuses on growth, adaptability and transformational change (Giberson et al., 2009). Resource management for one agency included exploring new ways to fund needed programs, such as using braided funding in partnership with another state agency. Funding opportunities for some of these agencies included grants for activities for such as transition and setting aside funds for innovative programs deemed successful. Transformational leaders, who create organizational cultures of adhocracy, tend to facilitate learning environments that lead to innovation and the adoption of best practices.

\section{Summary and conclusions}

The review of the four state-federal VR agencies clearly indicated that VR practice environments and the likelihood of engaging in innovative best practices is affected by the organization in terms of their: culture, leadership, support for innovative and promising practices, partnerships, staff training and development, and the working alliance and client-centered services. These observations were further validated at all levels of each organization studied.

In resource-limited environments, evidence of efficacy and effectiveness can help make programmatic funding decisions so that agencies can show that the services they provide work (Brannon, 2010). The statefederal VR program has been challenged to demonstrate the effectiveness of VR services provided to eligible customers. The emphasis on the development and implementation of EBPs is needed to assist state-federal VR agencies in demonstrating the effectiveness of VR service provision. Creating cultures that transform agencies into learning organizations and that empower staff towards innovation is a critical and necessary step. Leadership continuity will also become a highly significant factor in the sustainability of these types of enabling organizational cultures. There is no question that VR agencies must develop a foundation of EBPs that lead to competitive employment outcomes for people with disabilities. Such practices are in need of metrics that can prove they work. Proven strategies and best promising practices must be documented and their portability to other state VR agencies needs to be considered. The agencies in the sample have all moved from hierarchal to adhocracy cultures, and created learning organizations that encourage staff at all levels to be innovative and employ effective best practices. Finding ways to measure the outcomes of best practices developed by agency staff continues to challenge VR organizations and is critically necessary to provide the level of empirical evidence of success to all the stakeholders in the state/federal VR program.

\section{Acknowledgments}

The contents of this article were developed with support from the Rehabilitation Research and Training Center on Evidence-Based Practice in Vocational Rehabilitation (RRTC-EBP VR) at the University of Wisconsin-Madison and the University of WisconsinStout and with funding provided by the U.S. 
Department of Education, National Institute on Disability and Rehabilitation Research (Grant H133B100034). The ideas, opinions, and conclusions expressed, however, are those of the authors and do not represent recommendations, endorsements, or policies of the U.S. Department of Education.

\section{References}

Anderson, C., Leahy, M. J., Del Valle, R., Sherman, S., \& Tansey, T. N. (2014). Methodological application of consensual qualitative research (CQR) to identify best practices and organizational factors in the public rehabilitation program. Journal of Vocational Rehabilitation, 41(2), 87-98.

Bass, B. M. (1985). Leadership: Good, better, best. Organizational Dynamics, 13(3), 26-40.

Bezyak, J. L., Ososkie, J. N., Trice, A. L., \& Yeager, P. (2010, Winter). The importance of counseling supervision in the professional development of public rehabilitation counselors. Journal of Applied Rehabilitation Counseling, 41(4), 30-35.

Brannon, R. (2010). Forward. Rehabilitation Education, 24, 177-178.

Brown, A. (1992). Organizational culture: The key to effective leadership and organizational development. Leadership \& Organization Development Journal, 13(2), 3-6.

Cameron, K., \& Quinn, R. (1999). Diagnosing and changing organizational culture based on the competing values framework. Boston, MA: Addison-Wesley.

Cameron, K. S., \& Quinn, R. E. (2006). Diagnosing and changing organizational culture: Based on the competing values framework. San Francisco: Jossey-Bass.

Chan, T., \& Reudel, K. (2005). A national report: The demand for and supply of qualified rehabilitation counselors. Washington, D.C.: American Institutes for Research.

Chi, H., Lan, C., \& Dorjgotov, B. (2012). The moderating effect of transformational leadership on knowledge management and organizational effectiveness. Social Behavior and Personality, 40(6), 1015-1024.

Chi, H., Lan, C., \& Dorjgotov, B. (2012). The moderating effect of transformational leadership on knowledge management and organizational leadership. Social Behavior and Personality, 40, 1015-1024.

De Long, D., \& Fahey, L. (2000). Diagnosing cultural barriers to knowledge management. Academy of Management Executive, 14(4), 113-127.

Del Valle, R., Leahy, M. J., Sherman S., Anderson C., Tansey, T. N., \& Schoen, B. (2014). Promising best practices that lead to employment in vocational rehabilitation: Findings from a fourstate multiple case study. Journal of Vocational Rehabilitation, 41(2), 99-113.

Fleming, A. R., Del Valle, R., Kim, M., \& Leahy, M. J. (2013). Best practice models of effective vocational rehabilitation service delivery in the public rehabilitation program: A review and synthesis of the empirical literature. Rehabilitation Counseling Bulletin, 56(3), 146-159.

Fontana, A., \& Frey, J. H. (2005). The interview: From neutral stance to political involvement. In N. K. Denzin and Y. S. Lincoln (Eds.), The SAGE handbook of qualitative research (3rd ed.), (pp. 695727). Thousand Oaks, CA: Sage Publications, Inc.
Fraenkel, J. R., \& Wallen, N. E. (2003). How to design and evaluate research in education. New York, NY: McGraw-Hill.

Giberson, T. R., Resick, C. J., Dickson, M. W., Mitchelson, J. K., Randall, K. R., \& Clark, M. A. (2009). Leadership and organizational culture: Linking CEO characteristics to cultural values. Business Psychology, 24, 123-137.

Herbert, J. T. (2004). Analysis of clinical supervision practices as documented in rehabilitation counseling syllabi and fieldwork manuals. Rehabilitation Education, 18(1), 13-33.

Herbert, J. T., (1997) Quality assurance: Administration and supervision, In D. R. Maki \& T. F. Rigger (Eds.), Rehabilitation counseling profession and practice (pp.246-258). New York, NY: Springer.

Herbert, J. T., \& Trusty, J. (2006, Winter). Clinical supervision practices and satisfaction within the public vocational rehabilitation program. Rehabilitation Counseling Bulletin, 49(2), 66-80.

Hill, C. E., Thompson, B. J., \& Williams, E. N. (1997). A guide to conducting consensual qualitative research. The Counseling Psychologist, 25, 517-572.

Hill, C. E., \& Williams, E. N. (2012). The sample. In C.E. Hill (Ed.), Consensual qualitative research: A practical resource for investigating social science phenomena (pp.71-82). Washington, DC: American Psychological Association.

Ladany, N., Thompson, B. J., \& Hill, C. E. (2012). Cross-analysis. In C. E. Hill (Ed.), Consensual qualitative research: A practical resource for investigating social science phenomena (pp. 117-134). Washington, DC: American Psychological Association.

Leahy, M. J., Del Valle, R., Fleming, A. R., \& Kim, M. (2012). Research protocol: Multiple case studies on effective vocational rehabilitation service delivery practices. (pp. 173-176). Lansing, MI: Rehabilitation Research and Training Center on Effective VR Service Delivery Practices.

Leahy, M. J., Thielsen, V. T., Millington, M. J., Austin, B., \& Fleming, A. (2009). Quality assurance and program evaluation: Terms, models, and applications in rehabilitation administration. Journal of Rehabilitation Administration, 33(2), 69-82.

Leahy, M. J., Del Valle, R. J., Sherman, S. G., Anderson, C., Tansey, T., Lui, J., \& Fitzgerald, S. (2013). Phase II final report: Multiple case studies on effective vocational rehabilitation services delivery practices. Lansing, MI: Rehabilitation Research and Training Center on Effective VR Service Delivery Practices.

Lincoln, S. (2010). From the individual to the world: How the competing values framework can help organizations improve global strategic Performance. Emerging Leadership Journeys, 4(1), 3-9.

Lucas, C., \& Kline, T. (2008). Understanding the influence of organizational culture and group dynamics on organizational learning and change. The Learning Organization, 15(3), 277287.

Merriam, S. B. (2009). Qualitative research: A guide to design and implementation. San Francisco, CA: Jossey-Bass.

Mezirow, J. (2000). Learning to think like an adult: Core concepts of transformational learning. Learning as transformation: Critical perspectives on a theory in progress. San Francisco: Jossey-Bass.

Millington, M. J., \& Schultz, J. C. (2009). The challenge of organizational culture in quality assurance implementation. Journal of Rehabilitation Administration, 33(2), 121-129.

Naranjo-Valencia, J. C., Jimenez-Jimenez, D., \& Sanz-Valle, R. (2011). Innovation or imitation? The role of organizational culture. Management Decision, 49(1), 55-72. 
Packard, T. (2009). Leadership and performance in human services organizations. In R. J. Patti (Ed.), The handbook of human services management (pp. 143-164). Thousand Oaks, CA: Sage.

Patterson, J. B., Bruyere, S., Szymanski, E. M., \& Jenkins, W. (Eds.). (2005). Philosophical, historical, and legislative aspects of the rehabilitation counseling profession. Rehabilitation Counseling: Basics and Beyond (pp. 27-54). Austin, TX: Pro-ed.

Pruett, S. R., Swett, E. A., Chan, F., Rosenthal, D. A., \& Lee, G. K. (2008). Empirical evidence supporting the effectiveness of vocational rehabilitation. Journal of Rehabilitation, 74(2), 56-63.

Rijal, S. (2010). Leadership style and organizational culture in learning organization: A comparative study. International Journal of Management and Information Systems, 14(5), 119-127.

Sanz-Valle, R., Naranjo-Valencia, J. C., Jimenez-Jimenez, D., \& Perez-Caballero, L. (2011). Linking organizational learning with technical innovation and organizational culture. Journal of Knowledge Management, 15(6), 997-1015.

Schein, E. H. (1984). Coming to a new awareness of organizational culture. Sloan Management Review, Winter, 3-16.

Schein, E. H. (1992). Organizational culture and leadership. San Francisco, CA: Jossey-Bass.

Schein, E. H. (1993). On dialogue, culture, and organizational learning. Organizational Dynamics, 22, 40-51.

Schein, E. H. (1997). Organizational culture and leadership. Retrieved from http://www.tnellen.com/ted/tc/schein.html

Schlosser, L. Z., Dewey, J. H., \& Hill, C. E. (2012). Auditing. In C.E. Hill (Ed.), Consensual qualitative research: A practical resource for investigating social science phenomena (pp. 135-144). Washington, DC: American Psychological Association.

Schraeder, M., Tears, R. S., \& Jordan, M. H. (2005). Organizational culture in public sector organizations. Leadership and Organizational Development Journal, 26(5/6), 492-502.

Schultz, J. C. (2007). Addressing national concerns through supervision: The role of the rehabilitation agency supervisor. Journal of Applied Rehabilitation Counseling, 38(4), 11-18.
Schultz, J. C. (2008). The tripartite model of supervision for rehabilitation counselors. Journal of Applied Rehabilitation Counseling, 39(1), 36-41.

Senge, P. (1994). The fifth discipline: The art and practice of the learning organization. New York: Currency Doubleday.

Sessa, V. I., \& London, M. (2006). Continuous learning: Individual, group, and organizational perspectives. Mahwah, NJ: Lawrence Erlbaum Associates.

Shahzad, F., Luqman, R. A., Khan, A. R., \& Shabbir, L. (2012). Impact of organizational culture on organizational performance: An overview. Interdisciplinary Journal of Contemporary Research in Business, 3(9), 975-985.

Stake, R. E. (2005). Qualitative case studies. In N.K. Denzin and Y.S. Lincoln (Eds.), The SAGE handbook of qualitative research: Third edition (pp. 443-466). Thousand Oaks, CA: Sage Publications, Inc.

Stake, R. E. (2006). Multiple case study analysis. New York: Guilford Press.

Stone, A. G., Russell, R. F., \& Patterson, K. (2004). Transformational versus servant leadership: A difference in leader focus. Leadership \& Organizational Development Journal, 25(3/4), 349-361.

Tuft, K. A. (2012). A research study of transformational leadership comparing leadership styles of the principal (Doctoral Dissertation.). Retrieved from http://www.duq.edu/Documents/education/_pdf/DEFL/dissertations/20120309-luft.pdf.

Warrick, D. D. (2011). The Urgent need for skilled transformational leaders: Integrating transformational leadership and organization development. Journal of Leadership, Accountability and Ethics, $8(5), 11-26$

Yang, F., Wu, M., Chang, C., \& Chien, Y. (2011). Elucidating the relationships among transformational leadership, job satisfaction, commitment foci and commitment bases in the public sector. Public Personnel Management, 40(3), 265-277.

Yin, R. K. (2009). Case Study Research: Design and Methods (4th ed.). Washington DC: Sage. 